\title{
Correlation between pathogenic species and clinical findings, disease severity, and visual outcome in patients with fungal keratitis
}

\section{Correlação entre espécies patogênicas e achados clínicos, gravidade da doença e desfecho visual em pacientes com ceratite fúngica}

\author{
Leidiane Adrinano Pereira', Rosália Antunes Foschini', Sidney Júlio de Faria e Sousa’ \\ 1. Departamento de Oftalmologia, Otorrinolaringologia e Cirurgia de Cabeça e Pescoço, Hospital das Clínicas, Faculdade de Medicina de Ribeirão \\ Preto, Universidade Estadual de São Paulo, Ribeirão Preto, SP, Brazil.
}

\begin{abstract}
Purpose: To determine whether a correlation exists between pathogenic species and clinical findings, disease severity, and visual outcome in patients with keratitis and fungal growth in microbiological culture. Methods: A retrospective study of patients with fungal growth in the microbiological culture of corneal scrapings. Patients were treated at an ophthalmologic reference center in Southeastern Brazil from January 1992 to October 2015. Results: Medical records of 181 patients ( 131 males and 50 females) with a mean age of 47 \pm 18 years were analyzed. The three most common etiologies were Fusarium sp. (38.7\%), Aspergillus sp. (15\%), and Candida sp. (13.2\%). Among these, Fusarium sp. was the most frequent in patients aged $\leq 50$ years $(p=0.002)$ and in those with a recent history of a foreign body and/or ocular trauma $(p=0.01)$. Candida sp. was the most frequent etiology in patients aged $>50$ years $(p=0.002)$, in those with postoperative ocular surgery $(p=0.002)$; in those with a previous ocular pathology $(p=0.0007)$; and in immunodepressed patients $(p=0.0004)$. Conclusion: Fusarium sp. was predominant in patients aged $\leq 50$ years and those with a recent history of foreign body and/or ocular trauma, whereas Candida sp. was predominant in older adults, in those with a postoperative ocular surgery, in those with a previous ocular pathology, and in immunodepressed patients.
\end{abstract}

Keywords: Keratitis; Eye infections, fungal; Corneal ulcer; Risk factors
RESUMO | Objetivo: Determinar se existe uma correlação entre espécies patogênicas e achados clínicos, gravidade da doença e resultado visual em pacientes com ceratite e crescimento de fungos em cultura microbiológica. Métodos: Estudo retrospectivo de pacientes com crescimento de fungos na cultura microbiológica de raspado de córnea. Os pacientes foram tratados em um centro de referência oftalmológica no Sudeste do Brasil de janeiro de 1992 a outubro de 2015. Resultados: Foram analisados registros médicos de 181 pacientes (131 homens e 50 mulheres) com idade média de $47 \pm 18$ anos. As três etiologias mais comuns foram Fusarium sp. (38,7\%), Aspergillus sp. (15\%) e Candida sp. (13,2\%). Entre estas, Fusarium sp. foi a mais frequente em pacientes com idade $\leq 50$ anos $(p=0,002)$ e naqueles com história recente de corpo estranho e/ou trauma ocular $(p=0,01)$. Candida sp. foi a etiologia mais frequente em pacientes com idade $>50$ anos $(p=0,002)$, naqueles com cirurgia ocular pós-operatória ( $p=0,002)$; naqueles com patologia ocular prévia ( $p=0,0007)$; e em pacientes imunodeprimidos $(p=0,0004)$. Conclusão: Fusarium sp. foi predominante em pacientes com idade $\leq 50$ anos e naqueles com história recente de corpo estranho e/ou trauma ocular; enquanto Candida sp. foi predominante em adultos mais velhos, naqueles com cirurgia ocular pós-operatória, naqueles com patologia ocular prévia e em pacientes imunodeprimidos.

Descritores: Ceratite; Infecções oculares fúngicas; Úlcera da córnea; Fatores de risco

\section{INTRODUCTION}

Microbial keratitis is one of the most common causes of preventable blindness worldwide ${ }^{(1)}$. Several studies published in the literature have reported that several classes of bacteria, fungi, viruses, and parasites as etiologic agents of corneal ulcers ${ }^{(1-5)}$.

Fungal keratitis is typically characterized by a dry, raised lesion with feathered/hyphenated edges, in addition to satellite lesions and hypopyon ${ }^{(6)}$. 
Pathogens that are isolated in a microbiological culture of human corneas with keratomycosis are more frequently filamentous fungi, such as Fusarium sp. and Aspergillus $\mathrm{sp}^{(7,8)}$.

Conventional methods for the diagnosis of fungal keratitis include Gram, $10 \%$ potassium hydroxide monoxide, lactophenol cotton blue, Giemsa, or calcofluor white staining $^{(9-11)}$. Sabouraud dextrose agar is a culture medium that is widely used to isolate fungi ${ }^{(10)}$.

Risk factors associated with a higher predisposition for fungal keratitis include ocular trauma, often with tree branches; the incorrect use and improper cleaning of contact lenses; preexisting ocular surface disorders, such as dry eye disease and herpetic keratitis; systemic diseases, such as decompensated diabetes mellitus and immunodepression; and prolonged use of antibiotics ${ }^{(12,13)}$.

Mycotic keratitis presents an important aggravating factor in that it affects individuals with a low socioeconomic and cultural status, particularly rural workers, a population often affected by microbial keratitis in their work environment and who often do not have eye protection. In addition to this greater predisposition, patients often delay seeking treatment in a specialized center, which worsens the final visual acuity (VA) results ${ }^{(14)}$. Despite high cost implications and poor visual outcomes following treatment, it does not attract as much attention as other eye conditions such as cataracts, refractive errors, and childhood blindness ${ }^{(15)}$.

Fungal keratitis can lead to serious complications including endophthalmitis, perforation, and blindness, particularly in cases where patients are not well conducted. Ophthalmologists continue to seek the most effective treatment modalities for these patients ${ }^{(8)}$.

Yeasts are thought to be associated with systemic immunosuppression, whereas filamentous fungi are most often present in cases of ocular trauma in individuals involved in agricultural activities ${ }^{(15)}$. As previously observed, a larger infiltration leads to a poorer visual outcome and older age and males are more associated with a poor vision $^{(16)}$.

Few published studies have reported on correlations between the pathogenic species and clinical characteristics in fungal keratitis.

The present study was conducted to determine correlations between the pathogenic species and demographic data, clinical status, disease severity, and visual outcomes in patients with fungal keratitis who were treated at an ophthalmologic reference center in Southeastern Brazil.

\section{METHODS}

This study was approved by the local Ethics Committee following the principles of the Declaration of Helsinki.

This study was a retrospective survey of medical records of 181 patients treated at the Clinic's Hospital of Ribeirão Preto, University of São Paulo, Southeastern Brazil, and patients who had fungal growth in an ocular material (corneal scrapings) cultivated in a microbiological culture medium were included from January 1992 to October 2015.

All corneal scrapings were removed using a sterile Kimura spatula following an application of anesthetic eye drops. Corneal scrapings were routinely seeded in the following culture media: chocolate and blood agar plates, Sabouraud agar, and thioglycollate broth.

The following information was extracted from the medical records: demographic and occupational data, culture results, predisposing factors for fungal keratitis, symptoms and their duration, corneal biomicroscopy findings, and VA after treatment.

The Access database (Microsoft Corporation, Seattle, Washington, USA) was used to record and store survey data.

Statistical analyses were performed using Student's $t$ test for continuous data and percentages or Fisher's exact test for categorical data. $\mathrm{p}<0.05$ was considered statistically significant.

\section{RESULTS}

\section{Epidemiological results}

Medical records of 181 [131 (72.4\%) males and 50 (27.6\%) females] patients with a mean age of $47 \pm 18$ years were analyzed.

The primary work activity reported by patients was agriculture (29.8\%).

The three most frequent etiologies of fungal keratitis were Fusarium sp. (38.7\%), Aspergillus sp. (15\%), and Candida sp. (13.2\%).

Candida $s p$. was most prevalent in patients aged $>50$ years $(p=0.002)$, and Fusarium sp. had a higher predisposition in those aged $\leq 50$ years $(p=0.002)$.

Table 1 illustrates the etiology of fungal keratitis (Fusarium sp., Aspergillus sp., and Candida sp.) and patients' epidemiological characteristics.

\section{Clinical evaluation}

Of the factors associated with fungal keratitis, 67 of $181(37 \%)$ patients had a recent history of foreign body 
(most often cited as dust) and/or ocular trauma, 27 (15\%) had an ocular pathology history (e.g., glaucoma, dry eye, bullous keratopathy, recurrent herpes, diabetic retinopathy, or keratoconus), 26 (14.4\%) had a recent ocular surgery (e.g., cataract surgery, corneal/conjunctival surgery, vitrectomy, or corneal transplantation), and 12 (6.6\%) were immunoexpressed (e.g., acquired immunodeficiency syndrome, decompensated diabetes mellitus, chemotherapy, or use of systemic immunosuppressants).

Fusarium sp. had a higher prevalence in patients with a recent history of foreign body and/or ocular trauma $(p=0.01)$, whereas Candida sp. was more frequently observed in patients with a recent ocular surgery $(p=0.002)$, in those with previous ocular pathology $(p=0.0007)$, and in immunosuppressed patients $(p=0.0004)$.

Table 2 describes the etiology of fungal keratitis in association with patients' clinical aspects.

Ocular symptoms were described in 164 (90.6\%) of 181 medical records. Ocular pain appeared in 108 (65.8\%) records, and 65 (39.6\%) patients complained of foreign body sensation. Patients presented with ocular symptoms within a mean period of $16.0 \pm 21.6$ days. The time to symptom onset was not identified in 29 records.

Table 3 demonstrates the etiology of fungal keratitis and patients' ocular symptoms. There was no statistical difference between the etiology of fungal keratitis and patients' symptoms at the first consultation.

The mean size of the largest ulcer diameter at the first visit, measured using biomicroscopy examination, was $4.0 \pm 1.9 \mathrm{~mm}$ (data annotated in 92 cases). Twelve (6.6\%) of 181 presented melting, 18 (10\%) had descemetocele or corneal perforation, and 33 (18.2\%) had hypopyon formation. There was no statistical difference between the etiology of fungal keratitis and biomicroscopic findings at the first consultation (Table 4).

\section{Treatment evaluation}

In total, ulcer was cured in 28 (15.4\%) patients using antibiotic eye drops and without using antifungal medication despite the laboratory result of fungal growth in culture. However, bacterial growth associated with fungal growth was identified in the microbiological cul-

Table 1. Patients' epidemiological characteristics: comparison between the three main etiologies of fungal keratitis

\begin{tabular}{|c|c|c|c|c|}
\hline Characteristic & Fusarium sp. (\%) $n=70$ & Aspergillus sp. (\%) $n=27$ & Candida sp. $(\%) n=24$ & p-value Fisher's exact test \\
\hline Female & $16(22.8)$ & $10(37.0)$ & $11(45.8)$ & 0.070 \\
\hline Male & $54(77.1)$ & $17(62.9)$ & $13(54.2)$ & 0.070 \\
\hline Age $\leq 50$ years & $48(68.6)$ & $13(48.1)$ & $7(29.1)$ & 0.002 \\
\hline Age $>50$ years & $22(31.4)$ & $14(51.8)$ & $17(70.8)$ & 0.002 \\
\hline Rural workers & $23(32.8)$ & 8 (29.6) & $3(12.5)$ & 0.150 \\
\hline
\end{tabular}

Table 2. Comparison between the three main etiologies of fungal keratitis and the frequency of associated factors

\begin{tabular}{|c|c|c|c|c|}
\hline Associated factor & Fusarium sp. (\%) $n=70$ & Aspergillus sp. (\%) $n=27$ & Candida sp. (\%) n=24 & p-value Fisher's exact test \\
\hline Foreign body and/or ocular trauma & $27(38.6)$ & 7 (25.9) & $2(8.3)$ & 0.0100 \\
\hline Postoperative ocular surgery & $4(5.7)$ & $4(14.8)$ & $10(41.7)$ & 0.0002 \\
\hline Previous ocular pathology & $3(4.3)$ & $7(25.9)$ & $7(29.2)$ & 0.0007 \\
\hline Immunodepression & $1(1.4)$ & $4(14.8)$ & $5(20.8)$ & 0.0004 \\
\hline
\end{tabular}

Table 3. Patients' ocular symptoms: comparison between the three main etiologies of fungal keratitis

\begin{tabular}{|c|c|c|c|c|}
\hline Ocular symptom & Fusarium sp. (\%) $n=66$ & Aspergillus sp. (\%) $n=23$ & Candida sp. (\%) $n=20$ & $p$-value Fisher's exact test \\
\hline Pain & $45(68.2)$ & $14(60.9)$ & $17(85)$ & 0.2 \\
\hline Foreign body sensation & 27 (40.9) & $10(43.5)$ & $6(30)$ & 0.7 \\
\hline
\end{tabular}

Table 4. Comparison between the three main etiologies of fungal keratitis and biomicroscopy examination at the first visit

\begin{tabular}{|c|c|c|c|c|}
\hline Biomicroscopic finding & Fusarium sp. (\%) $n=68$ & Aspergillus sp. (\%) $n=27$ & Candida sp. (\%) $n=24$ & p-value Fisher's exact test \\
\hline Melting & $9(13.2)$ & 0 & $1(4.2)$ & 0.09 \\
\hline Descemetocele/corneal perforation & $5(7.3)$ & $4(14.8)$ & $5(20.8)$ & 0.16 \\
\hline Hypopyon & $15(22.0)$ & $5(18.5)$ & $3(12.5)$ & 0.63 \\
\hline
\end{tabular}


ture in $24(85.7 \%)$ of 28 patients, thereby illustrating the response to antibiotic treatment.

Ulcer healing was observed in 9 (17.3\%) patients who were administered antiherpetic medication associated with antifungal treatment. Therefore, in these patients, a secondary fungal infection in the herpetic ulcers was assumed.

The mean time of antifungal treatment was $51.0 \pm 33.5$ days, and the mean treatment time did not differ among Candida sp., Fusarium sp., or Aspergillus sp.

\section{Visual acuity after treatment}

The final VA could not be obtained in 137 (75.7\%) of 181 medical records, and it was $>0.5$ (logMAR $<0.3$ ) in 27 (19.7\%), between 0.2 and 0.5 (logMAR 0.7-0.3) in 22 $(16.0 \%)$, and $\leq 0.1$ (logMAR $\geq 0.8)$ in $88(64.2 \%)$ patients.

Table 5 shows the final VA after fungal keratitis treatment. The final VA was not statistically different among the three most frequent etiologies.

\section{DISCUSSION}

As described in other studies, the most prevalent ocular mycoses occur in men, often in rural workers, which is possibly attributable to their increased occupational exposure $^{(11,17-20)}$. In the present study, we showed a higher frequency of fungal ulcers in male patients $(72.4 \%)$, rural workers $(29.8 \%)$, and in those with a history of foreign body (more frequently cited as dust) and/or ocular trauma (37\%). These workers often lack eye protection while working in the fields, which thereby puts them at risk for eye damage and consequent fungal keratitis.

The mean age of patients treated for fungal keratitis was $47 \pm 18$ years; therefore, they are in the economically active age group, a circumstance that has been already reported in previous studies as an epidemiological characteristic of fungal keratitis ${ }^{(17-21)}$.

Ocular pain is a relevant symptom in patients with fungal keratitis (65.8\%) and must be carefully evaluated by an ophthalmologist seeking clinical evidence for the diagnosis of a mycotic ulcer.

The mean time of symptoms reported at the first consultation was high $(16.0 \pm 21.6$ days $)$, a situation that compromises a patient's visual recovery. A study conducted in London also found a high median range (3.4 weeks) from the onset of keratitis to the confirmation of fungal infection ${ }^{(22)}$.

Following treatment, we observed a higher prevalence of final VA $\leq 0.1(\log M A R \geq 0.8)$ in $88(64.2 \%)$ patients, independent of the fungal etiology. In addition, the final VA was not statistically different among the three most frequent etiologies. In addition, another study has found similar visual outcomes between patients with Candida infection and those with filamentous fungal infection ${ }^{(22)}$.

Our laboratory results did not differ from published data in the literature, which have reported a higher prevalence of fungal keratitis caused by Fusarium sp., Aspergillus sp., Candida sp., among others ${ }^{(3,17,23-26)}$.

In the present study, Fusarium sp. was found to be the most frequent etiology, particularly in patients aged $\leq 50$ years, in addition to ocular trauma. A Brazilian study published in 2005 and a Danish study identified ocular trauma as a risk factor for filamentous fungal keratitis ${ }^{(27,28)}$. Researchers from South Florida in the U.S. have found that ocular trauma was particularly prevalent with infections caused by Fusarium sp ${ }^{(29)}$. Similarly, a study in London also found that ocular trauma is a major risk factor for filamentous fungal infection ${ }^{(22)}$.

This study demonstrated that Candida sp. is more frequent in patients with recent ocular surgery, previous ocular pathology, and immunosuppression. In addition, other studies have found that ocular surgeries and previous eye diseases are associated with yeast keratitis $^{(22,27,28)}$.

Data extracted from medical records revealed 28 patients whose ulcer was cured without using antifungal medication despite fungal growth in microbiological scrapings. This situation can be characterized according to information from previous studies showing a possible discrepancy between microbiology results and patients' clinical findings as detailed below.

1) False-positive cultures: (I) when fungus colonization is identified in the patient, (II) when there is fungal contamination in the laboratory, (III) when the sample comes from two different areas, or (IV) when the pathological specimen is not adequately analyzed ${ }^{(29)}$.

Table 5. Patients' visual acuity (VA) after treatment: comparison between the three main etiologies of fungal keratitis

\begin{tabular}{lcccc}
\hline VA after treatment & Fusarium sp. $(\%) \mathbf{n = 5 5}$ & Aspergillus sp. (\%) $\mathbf{n = 2 2}$ & Candida sp. (\%) $\mathbf{n = 1 8}$ & $p$-value Fisher's exact test \\
\hline$>0.5(\log M A R<0.3)$ & $12(21.8)$ & $3(13.6)$ & $2(11.1)$ & 0.47 \\
$0.2-0.5(\log M A R ~ 0.7-0.3)$ & $10(18.2)$ & $2(9.0)$ & $2(11.1)$ & 0.67 \\
$\leq 0.1(\log M A R \geq 0.8)$ & $33(60.0)$ & $17(77.3)$ & $14(77.8)$ & 0.22 \\
\hline
\end{tabular}


This shows that clinical and microbiological findings should be evaluated together.

2) False-negative cultures: (l) when the tissue in the microbiology laboratory is crushed and fungal cells are destroyed, (II) when the fungus in the tissue is not viable, or (III) when the sample comes from two different areas ${ }^{(30)}$. These conditions did not occur in our study because our starting point was patients with corneal ulcers and positive fungal cultures.

Because the starting point for our study was microbiological growth data of fungi in ocular material culture, cases of fungal keratitis without culture growth were not included. There is a technical difficulty in confirming fungal growth in microbiological cultures, which occurs within 3-4 days, but culture media may require up to 4-6 weeks of incubation ${ }^{(8)}$.

Because our study was retrospective, some difficulties were encountered with data collection. For example, information on symptoms and disease time before treatment at the corneal outpatient clinic were not found in some cases, whereas in others, there was no description of ulcer size and VA information after treatment.

In conclusion, this study presented an impressive sample of cases of fungal keratitis that were sufficiently diagnosed using microbiological cultures. In addition, the study identified clinical features associated with the three major pathogenic species of serious ocular disease, in which an early diagnosis remains a challenge in most ophthalmological services, particularly in the developing countries.

\section{REFERENCES}

1. Gopinathan U, Garg P, Fernandes M, Sharma S, Athmanathan S, Rao GN. The epidemiological features and laboratory results of fungal keratitis: a 10-year review at a referral eye care center in South India. Cornea. 2002;21(6):555-9.

2. Leck AK, Thomas PA, Hagan M, Kaliamurthy J, Ackuaku E, John $M$, et al. Aetiology of suppurative corneal ulcers in Ghana and south India, and epidemiology of fungal keratitis. Br J Ophthalmol. 2002;86(11):1211-5.

3. Bharathi MJ, Ramakrishnan R, Vasu S, Meenakshi R, Palaniappan R. Epidemiological characteristics and laboratory diagnosis of fungal keratitis. A three-year study. Indian J Ophthalmol. 2003;51(4):315-21.

4. Sharma S, Garg P, Rao GN. Patient characteristics, diagnosis, and treatment of non-contact lens related Acanthamoeba keratitis. Br J Ophthalmol. 2000;84(10):1103-8.

5. Green M, Apel A, Stapleton F. Risk factors and causative organisms in microbial keratitis. Cornea. 2008;27(1):22-7.

6. Maharana PK, Sharma N, Nagpal R, Jhanji V, Das S, Vajpayee RB. Recent advances in diagnosis and management of Mycotic Keratitis. Indian J Ophthalmol. 2016;64(5):346-57.

7. Asbell P, Stenson S. Ulcerative keratitis. Survey of 30 years' laboratory experience. Arch Ophthalmol. 1982;100(1):77-80.
8. Thomas PA, Kaliamurthy ). Mycotic keratitis: epidemiology, diagnosis and management. Clin Microbiol Infect. 2013;19(3):210-20.

9. Gower EW, Keay LJ, Oechsler RA, lovieno A, Alfonso EC, Jones DB, et al. Trends in fungal keratitis in the United States, 2001 to 2007. Ophthalmology. 2010;117(12):2263-7.

10. Garg P. Fungal, mycobacterial, and nocardia infections and the eye: an update. Eye (Lond). 2012;26(2):245-51.

11. Revankar SG, Sutton DA. Melanized fungi in human disease. Clin Microbiol Rev. 2010;23(4):884-928.

12. Thomas PA. Current perspectives on ophthalmic mycoses. Clin Microbiol Rev. 2003;16(4):730-97.

13. Slowik M, Biernat MM, Urbaniak-Kujda D, Kapelko-Slowik K, Misiuk-Hojlo M. Mycotic infections of the eye. Adv Clin Exp Med. 2015;24(6):1113-7.

14. Alvarez-de-Carvalho AC, Iran-Ruthes $H$, Maia $M$, Yana D, Teruo-Sato $M$, Moreira $\mathrm{H}$, et al. [Fungal keratitis in the State of Parana-Brazil: clinical, epidemiological and diagnostic findings]. Rev Iberoam Micol. 2001;18(2):76-8. Portuguese.

15. Prajna VN, Prajna L, Muthiah S. Fungal keratitis: the Aravind experience. Indian J Ophthalmol. 2017;65(10):912-9.

16. Prajna NV, Krishnan T, Mascarenhas J, Srinivasan M, Oldenburg CE, Toutain-Kidd CM, et al. Predictors of outcome in fungal keratitis. Eye (Lond). 2012;26(9):1226-31.

17. Kibret T, Bitew A. Fungal keratitis in patients with corneal ulcer attending Minilik Il Memorial Hospital, Addis Ababa, Ethiopia. BMC Ophthalmol. 2016;16(1):148.

18. Upadhyay MP, Karmacharya PC, Koirala S, Tuladhar NR, Bryan LE, Smolin G, et al. Epidemiologic characteristics, predisposing factors, and etiologic diagnosis of corneal ulceration in Nepal. Am J Ophthalmol. 1991;111(1):92-9.

19. Kunimoto DY, Sharma S, Garg P, Gopinathan U, Miller D, Rao GN. Corneal ulceration in the elderly in Hyderabad, south India. Br J Ophthalmol. 2000;84(1):54-9.

20. Badawi AE, Moemen D, El-Tantawy NL. Epidemiological, clinical and laboratory findings of infectious keratitis at Mansoura Ophthalmic Center, Egypt. Int J Ophthalmol. 2017;10(1):61-7.

21. Cheikhrouhou F, Makni F, Neji S, Trigui A, Sellami H, Trabelsi H, et al. Epidemiological profile of fungal keratitis in Sfax (Tunisia). J Mycol Med. 2014;24(4):308-12.

22. Galarreta DJ, Tuft SJ, Ramsay A, Dart JK. Fungal keratitis in London: microbiological and clinical evaluation. Cornea. 2007;26(9):1082-6.

23. Saha S, Banerjee D, Khetan A, Sengupta J. Epidemiological profile of fungal keratitis in urban population of West Bengal, India. Oman J Ophthalmol. 2009;2(3):114-8.

24. Thomas PA. Fungal infections of the cornea. Eye (Lond). 2003;17(8): 852-62.

25. Ranjini CY, Waddepally VV. Microbial profile of corneal ulcers in a tertiary care hospital in South India. J Ophthalmic Vis Res. 2016;11(4):363-7.

26. Zbiba W, Baba A, Bouayed E, Abdessalem N, Daldoul A. A 5-year retrospective review of fungal keratitis in the region of Cap Bon. J Fr Ophtalmol. 2016;39(10):843-8.

27. Hofling-Lima AL, Forseto A, Duprat JP, Andrade A, Souza LB, Godoy $\mathrm{P}$, et al. [Laboratory study of the mycotic infectious eye diseases and factors associated with keratitis]. Arq Bras Oftalmol. 2005;68(1):21-7. Portuguese.

28. Nielsen SE, Nielsen E, Julian HO, Lindegaard J, Hojgaard K, Ivarsen A, et al. Incidence and clinical characteristics of fungal keratitis in a Danish population from 2000 to 2013. Acta Ophthalmol. 2015;93(1):54-8.

29. Rosa RH, Jr., Miller D, Alfonso EC. The changing spectrum of fungal keratitis in south Florida. Ophthalmology. 1994;101(6):1005-13.

30. Guarner J, Brandt ME. Histopathologic diagnosis of fungal infections in the 21st century. Clin Microbiol Rev. 2011;24(2):247-80. 